\title{
A multiplex endpoint RT-PCR assay for quality assessment of RNA extracted from formalin-fixed paraffin-embedded tissues
}

\author{
Elena A Takano ${ }^{1 \dagger}$, Thomas Mikeska ${ }^{1,2^{*}+}$, Alexander Dobrovic ${ }^{1,2}$, David J Byrne ${ }^{1}$, Stephen B Fox ${ }^{1,2}$
}

\begin{abstract}
Background: RNA extracted from formalin-fixed paraffin-embedded (FFPE) samples is chemically modified and degraded, which compromises its use in gene expression studies. Most of the current approaches for RNA quality assessment are not suitable for FFPE derived RNA.

Results: We have developed a single-tube multiplex endpoint RT-PCR assay specifically designed to evaluate RNA extracted from FFPE tissues for mRNA integrity and performance in reverse transcription - quantitative real-time PCR (RT-qPCR) assays. This single-tube quality control (QC) assay minimises the amount of RNA used in quality control. mRNA integrity and the suitability of RNA for RT-PCR is evaluated by the multiplex endpoint RT-PCR assay using the TBP gene mRNA as the target sequence. The RT-PCR amplicon sizes, 92, 161, 252 and 300 bp, cover a range of amplicon sizes suitable for a wide range of RT-qPCR assays. The QC assay was used to evaluate RNA prepared by two different protocols for extracting total RNA from needle microdissected FFPE breast tumour samples. The amplification products were analysed by gel electrophoresis where the spectrum of amplicon sizes indicated the level of RNA degradation and thus the suitability of the RNA for PCR. The ability of the multiplex endpoint RT-PCR QC assay to identify FFPE samples with an adequate RNA quality was validated by examining the $C_{q}$ values of an RT-qPCR assay with an 87 bp amplicon.

Conclusions: The multiplex endpoint RT-PCR assay is well suited for the determination of the quality of FFPE derived RNAs, to identify which RT-PCR assays they are suitable for, and is also applicable to assess non-FFPE RNA for gene expression studies. Furthermore, the assay can also be used for the evaluation of RNA extraction protocols from FFPE samples.
\end{abstract}

\section{Background}

Formalin-fixed paraffin-embedded (FFPE) tissue samples are routinely used for diagnosis of disease. There is increasing interest in extracting RNA from these samples as the large numbers of archival FFPE samples constitute an invaluable resource for the investigation of diagnostic, prognostic or predictive disease associated alterations in gene expression (reviewed in [1]). Furthermore, these often represent the only diagnostic material available.

\footnotetext{
* Correspondence: Thomas.Mikeska@petermac.org

+ Contributed equally

'Molecular Pathology Research and Development Laboratory, Department of Pathology, Peter MacCallum Cancer Centre, East Melbourne, Victoria 3002,

Australia

Full list of author information is available at the end of the article
}

However, RNA extracted from FFPE specimens is extensively degraded and chemically modified, which compromises its use in PCR based applications (reviewed in [2]). Degradation of RNA is influenced by the time and storage conditions between sample collection and formalin fixation, the fixation process, and the conditions and length of the subsequent storage [3]. Chemical modifications of RNA are caused by formaldehyde and result in the addition of mono-methylol groups to RNA bases and subsequently in the formation of methylene bridges between RNA bases [4], and RNA-protein cross-links [5]. The addition of the monomethylol group is in principal reversible, but a considerable amount is still present after RNA purification [4].

Whereas the extent of chemical modifications of the RNA initially limits the PCR amplification size, with
C Biomed Central

() 2010 Takano et al; licensee BioMed Central Ltd. This is an Open Access article distributed under the terms of the Creative Commons Attribution License (http://creativecommons.org/licenses/by/2.0), which permits unrestricted use, distribution, and reproduction in any medium, provided the original work is properly cited. 
time RNA degradation becomes more important in determining the size of amplifiable PCR fragments [3]. The RNA fragment sizes from FFPE tissue are usually less than $300 \mathrm{bp}$ and may be less than $100 \mathrm{bp}$ [3,6-8].

The quality of the extracted RNA is a critical factor for both microarray based and reverse transcription - quantitative real-time PCR (RT-qPCR) gene expression experiments. Microarray based approaches are more sensitive to RNA degradation and chemical modifications [2], which potentially influence the gene expression data [9].

RT-qPCR assays are less affected by RNA degradation and chemical modifications especially when the RT-qPCR amplicon size is less than $100 \mathrm{bp}$ [10]. It is nevertheless an essential prerequisite to characterise the quality of the extracted RNA prior to its use in a gene expression study to evaluate its suitability for the planned application and to minimise data misinterpretation $[11,12]$.

RNA quality is often defined in terms of RNA purity and RNA integrity. RNA purity is spectrophotometrically determined by the $\mathrm{A}_{260} / \mathrm{A}_{280}$ and $\mathrm{A}_{260} / \mathrm{A}_{230}$ absorbance ratios [13-15]. Both ratios are used to evaluate the level of contaminants such as proteins and residual organic compounds present in a RNA sample. These values provide no information about RNA degradation and amplifiable PCR amplicon sizes.

RNA integrity evaluates the level of RNA degradation and several methods have been developed for RNA integrity assessment. Two of the most commonly used approaches are suitable for assessing moderately degraded RNA but not highly degraded RNA.

The first approach investigates the ratio between the $28 \mathrm{~S}$ and $18 \mathrm{~S}$ ribosomal RNA bands and presumes that the integrity of ribosomal RNA reflects the integrity of mRNA [16,17]. The typical RNA fragment sizes of less than 300 bp make this methodology unsuitable for highly degraded RNA from FFPE samples [8]. Furthermore, this approach does not take chemical modifications of the RNA into account and provides no information on how the extracted RNA performs in RT-PCR.

The second approach has been adopted from a common practice in microarray experiments [18] and determines the mRNA integrity by utilising RT-qPCR assays to assess the 3':5' ratio of a gene target sequence, such as GAPDH [19] or ACTB [12]. These assays need to reach a considerable fragment size (up to $1.2 \mathrm{~kb}$ ) to calculate the 3':5' ratio, which makes this methodology unsuitable for highly degraded RNA from FFPE samples. Moreover, the 3':5' assays utilise an oligo- $\mathrm{dT}$ primer for cDNA preparation, which precludes the cDNA obtained from being used in the majority of RT-PCR assays, an important factor when the amount of RNA is often limited.

The third approach assesses a range of fragment sizes generated by (multiplexed) endpoint RT-PCR assays for certain reference (housekeeping) genes, such as G6PD, TBP, HPRT and ACTB [3,20-22]. This approach takes both fragmentation and chemical modifications of the RNA into account and determines the PCR amplicon sizes, which might be obtained in a PCR based application. When the PCR amplicon sizes cover a range from less than $100 \mathrm{bp}$ to several hundred base pairs, this methodology is suitable to assess the extent of the degradation of RNA extracted from FFPE tissues.

In this study, we sought to combine the best features of assays from the third approach to develop a readily performable endpoint RT-PCR assay to assess RNA extracted from FFPE samples for mRNA integrity and RNA performance in RT-qPCR assays.

The assay utilises the TBP (TATA box binding protein) reference gene mRNA as the target sequence. TBP has been shown to be relatively stably expressed in a range of tissues [23] and various tumour types (e.g. [24-29]). Four different amplicon sizes are amplified in parallel in a single tube from cDNA (multiplexed endpoint RT-PCR assay) to minimise the consumption of what are often limited amounts of RNA. The amplicon sizes chosen cover a range of up to $300 \mathrm{bp}$ and are therefore tailored to the fragment size limitations typically observed for RNA extracted from FFPE samples and PCR amplicon sizes usually used for the vast majority of RT-qPCR assays.

Our improved multiplex endpoint RT-PCR assay is a robust and convenient method which overcomes the limitations of current approaches for the quality assessment of RNA extracted from FFPE specimens. The assay has been thoroughly validated by assessing the quality of 180 RNA samples extracted from FFPE tissues with an RT-qPCR assay.

\section{Results}

\section{Assessment of total RNA yield and purity using optical density}

The amount of total RNA extracted for each of the samples was measured by a NanoDrop ND-2000 spectrophotometer and is shown for each sample replicate in Figure 1. The estimated mean total RNA extracted for protocol 1 was $2.23 \mu \mathrm{g}(111.5 \mathrm{ng} / \mu \mathrm{L})$ with values ranging from 0.24 to $14.24 \mu \mathrm{g}$ (12.0 to $712.0 \mathrm{ng} / \mu \mathrm{L})$. For protocol 2 , the estimated mean concentration was $2.76 \mu \mathrm{g}$ $(55.1 \mathrm{ng} / \mu \mathrm{L})$ with values ranging from 0.12 to $3.61 \mu \mathrm{g}$ (2.4 to $72.1 \mathrm{ng} / \mu \mathrm{L})$.

The corresponding absorbance ratio $A_{260} / A_{280}$ for each sample replicate is shown in Figure 1 . The mean $\mathrm{A}_{260} / \mathrm{A}_{280}$ ratio for protocol 1 was $1.8 \pm 0.2$ and for protocol $21.7 \pm 0.1$. The desired ratio $\mathrm{A}_{260} / \mathrm{A}_{280}$ is in the range of 1.7 to 2.1 and is dependent on the extraction conditions [30]. 


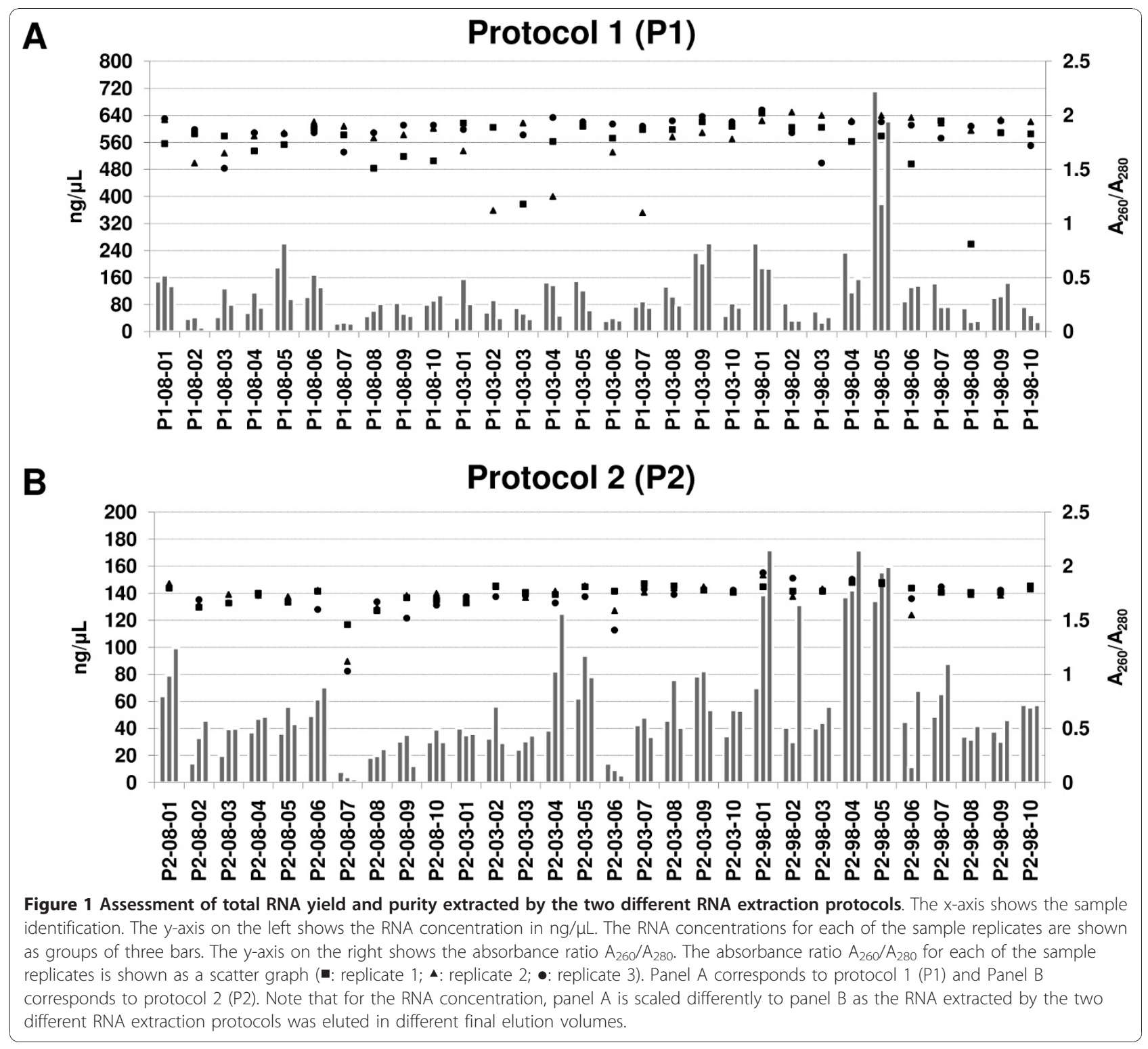

The use of the multiplex endpoint RT-PCR for assessment of mRNA integrity

The integrity of the mRNA extracted from each sample was assessed by the multiplex endpoint RT-PCR assay using the TBP (TATA box binding protein) mRNA (NM_003194) as the target sequence (Figure 2). The assay was designed to amplify four amplicons of 92, 161, 252 and 300 bp in parallel in a single tube (Figure 3).

The amplicons were designed to be amplified from cDNA but not genomic DNA (Figure 3). This is of particular importance for assessing cDNA synthesised from total RNA, which has not been treated with DNase. We used primer pairs where the primers were in exons spanning one or more introns (Figure 2). Furthermore, the primer locations were chosen to exclude known polymorphic sites from the primer binding sites.
The results for protocols 1 and 2 are summarised in Figures 4 and 5 for each sample replicate. In general, the least degraded RNA was extracted from the year 2003 samples for both protocols (Figures 4 and 5). In addition, the vast majority of sample replicates of both protocols amplified the $161 \mathrm{bp}$ and $252 \mathrm{bp}$ PCR fragments (Figures 4 and 5, Table 1).

\section{Assessment of mRNA performance by RT-qPCR}

The performance of the mRNA extracted from each sample was assessed by a RT-qPCR assay also using the TBP mRNA as the target sequence (Figure 2). The RTqPCR assay was designed and optimised to be monitored using hydrolysis probes from the Universal Probe Library (UPL) library in combination with gene-specific primers [31,32]. The assay amplifies an amplicon of 87 


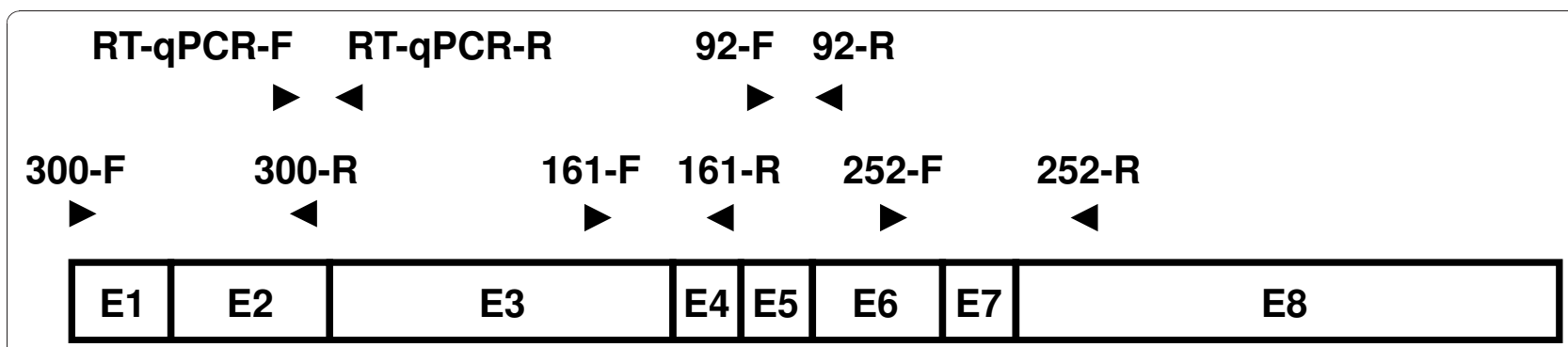

Figure 2 Primer placement for the multiplex endpoint RT-PCR and the RT-qPCR assay. Both assays use the TBP mRNA (NM_003194) as the target sequence. The eight exons are shown as rectangles labelled from E1 to E8. The primer locations are shown as horizontal arrow heads. The positions of the primers for the multiplex endpoint RT-PCR assay (92-F, 92-R, 161-F, 161-R, 252-F, 252-R, 300-F and 300-R) and for the RT-qPCR assay (RT-qPCR-F and RT-qPCR-R) are shown. Each primer pair was designed to span at least one intron.

bp from cDNA using an intron-spanning primer pair. The quantification cycle $\left(\mathrm{C}_{\mathrm{q}}\right)$ [33] values obtained for each sample replicate in the RT-qPCR assay were used to estimate the quantity of amplifiable template.

Each sample replicate was classified into one of three different groups based on the $\mathrm{C}_{\mathrm{q}}$ values measured $\left(\mathrm{C}_{\mathrm{q}} \leq\right.$ 32.0; $32.1 \leq \mathrm{C}_{\mathrm{q}} \leq 35.0 ; 35.1 \leq \mathrm{C}_{\mathrm{q}} \leq 39.9$ ) (Table 2). The $\mathrm{C}_{\mathrm{q}}$ value is inversely proportional to the number of amplifiable templates. $\mathrm{A}_{\mathrm{q}}$ value of 35 is generally considered as the limit for the detection of a single copy template [34,35]. A $\mathrm{C}_{\mathrm{q}}$ value above 35 thus represents less than one copy template present and can be considered as background noise of the RT-qPCR assay [35]. A theoretical $C_{q}$ value of 32 represents approximately 10 copies of the target template.
Eighty seven percent (78/90) of samples extracted by protocol 1 and $80 \%(72 / 90)$ of samples isolated by protocol 2 showed $\mathrm{C}_{\mathrm{q}}$ values less than 35.1 for the TBP RT-qPCR assay (Figures 4 and 5, Table 2). Therefore, cDNA prepared from RNA extracted with protocol 1 might had slightly more amplifiable templates per sample volume than cDNA prepared from total RNA extracted with protocol 2 .

Comparison of the multiplex endpoint RT-PCR and RTqPCR assays

The results from the multiplex endpoint RT-PCR assay were validated by the results obtained from the RTqPCR assay and allowed the identification of FFPE samples with an adequate RNA quality.

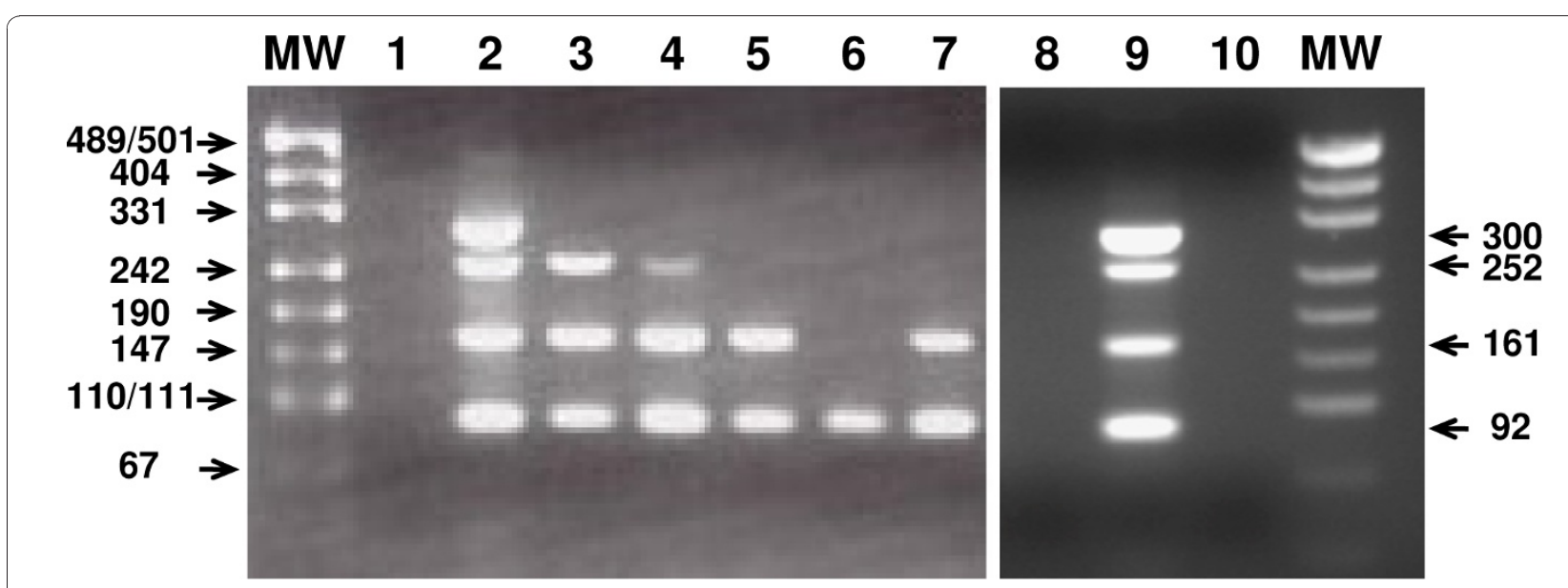

Figure 3 Assessment of RNA degradation and RNA performance in RT-PCR by the multiplex endpoint RT-PCR assay. The sizes of the molecular weight markers (MW) are given on the left, whereas the sizes of the TBP amplicons are indicated on the right. Sizes are given in base pairs. Lane 1 and 10 were loaded with the no template control (NTC). Lane 2 and 9 were loaded with the PCR reaction obtained from a CDNA mixture synthesised from RNA extracted from different cell lines and serves as positive control, showing all four PCR amplification products of the expected size. Lane 8 was loaded with the PCR reaction obtained from genomic DNA and served as negative control. Lanes 3 to 7 were loaded with RT-PCR reactions obtained from CDNAs synthesised from total RNA derived from needle microdissected FFPE breast tumour tissues (Lane 3: P1-98-05, replicate 1; Lane 4: P1-98-06, replicate 1; Lane 5: P1-98-07, replicate 1; Lane 6: P1-98-08, replicate 1; Lane 7: P1-98-09, replicate 1). 


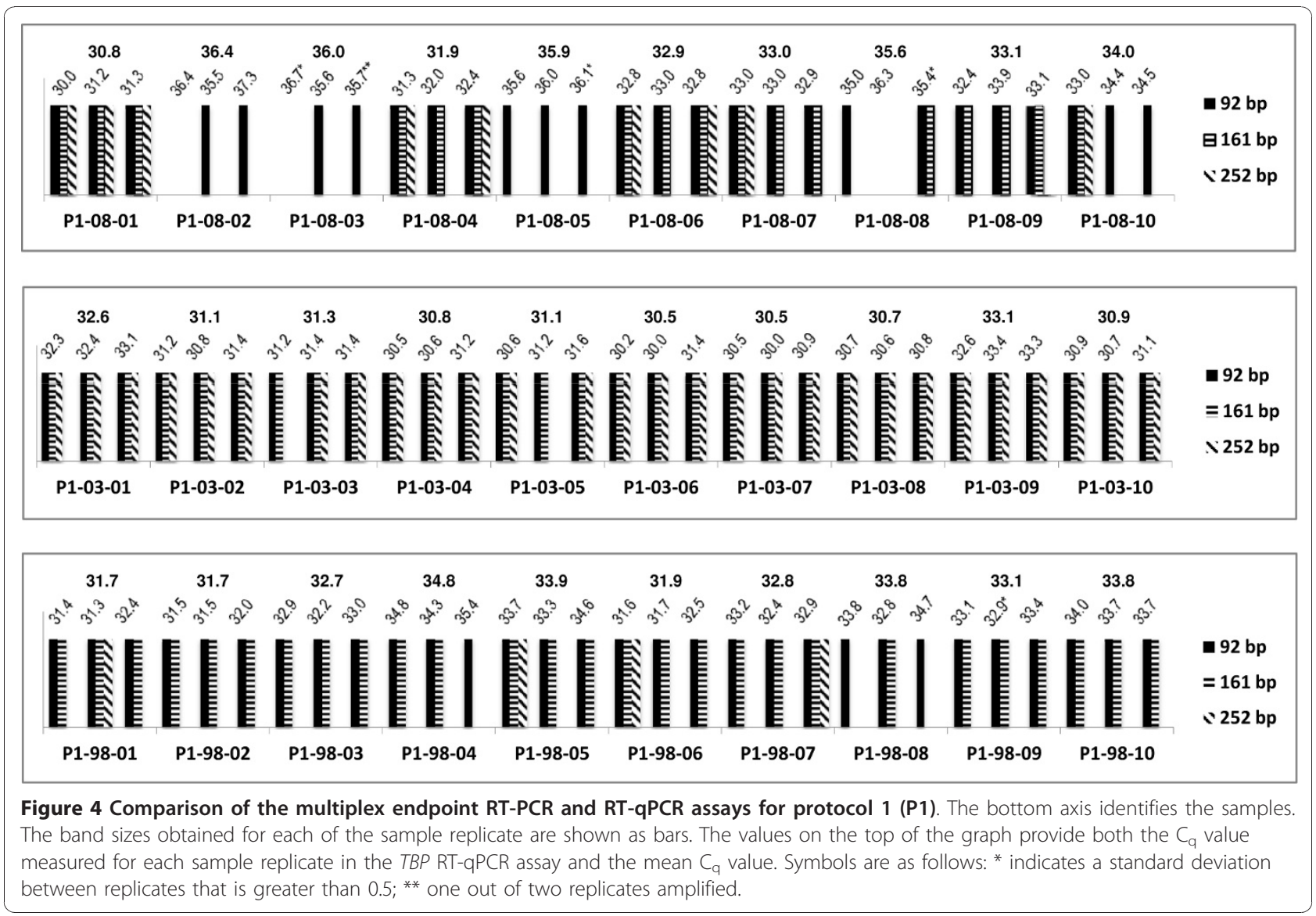

Almost all the samples (135/139) that amplified the PCR fragments more than $92 \mathrm{bp}$ in the multiplex endpoint RT-PCR assay amplified the 87 bp product at $\mathrm{C}_{\mathrm{q}}$ values less than 35.1 in the RT-qPCR assay consistent with a greater amount of amplifiable template (Figures 4 and 5, Table 1).

Six percent (10/180) of the samples did not amplify in the multiplex endpoint RT-PCR assay (Table 1). Consistent with this, the absence of the $92 \mathrm{bp}$ amplicon was associated with late amplification in the RTqPCR assay with a $\mathrm{C}_{\mathrm{q}}$ value later than 35.0 (Figures 4 and 5, Table 1).

In some cases, stochastic effects due to the very small number of available templates, can give inconsistent results; e.g. for one of the replicates of sample P2-08-08, the $92 \mathrm{bp}$ amplicon did not amplify in the multiplex endpoint RT-PCR assay but showed a band for the 161 bp product (Figure 5). The other replicates showed a 92 bp band and band sizes up to the $161 \mathrm{bp}$ amplicon, respectively. All three replicates showed $C_{q}$ values in the RT-qPCR assay above 35.0 (Figure 5) indicating that on average less than one copy of template was present.

We saw no FFPE samples that gave robust amplification for the $300 \mathrm{bp}$ amplicon. Forty six percent (41/90) of the samples prepared by protocol 1 amplified all the amplicons up to $252 \mathrm{bp}$ in the multiplex endpoint RTPCR assay (Figure 4). These samples showed a mean $C_{q}$ value in the RT-qPCR assay of $31.5 \pm 1.0$ with values ranging from 30.0 to 33.7. For protocol 2, 33\% (30/90) of the samples amplified the amplicons up to $252 \mathrm{bp}$ and showed a mean $C_{q}$ value of $31.7 \pm 0.8$ with values ranging from 31.7 to 33.3 (Figure 5).

Correlations between a longer amplicon size in the multiplex endpoint RT-PCR assay and the appropriate $\mathrm{C}_{\mathrm{q}}$ value obtained in RT-qPCR were evaluated by calculating the Spearman correlation coefficient. We found an inverse correlation for both parameters for protocols 1 and $2[r(\mathrm{P} 1)=-0.75, \mathrm{CI}(95 \%)=-0.83$ to $-0.65(P<$ $0.0001, \mathrm{n}=90)$ and $r(\mathrm{P} 2)=-0.80$, CI $(95 \%)=-0.86$ to $-0.70(P<0.0001, \mathrm{n}=90)$, respectively]. Thus, a longer fragment size in the multiplex endpoint RT-PCR assay was correlated with a smaller $\mathrm{C}_{\mathrm{q}}$ value in the RT-qPCR assay for both total RNA extraction protocols (Figure 6).

Interestingly, both the multiplex endpoint RT-PCR and the RT-qPCR assay show that the samples prepared from 2003 performed best during PCR amplification. All 60 samples from 2003 extracted by protocols 1 and 2 amplified PCR amplicons up to $161 \mathrm{bp}$ in the multiplex 


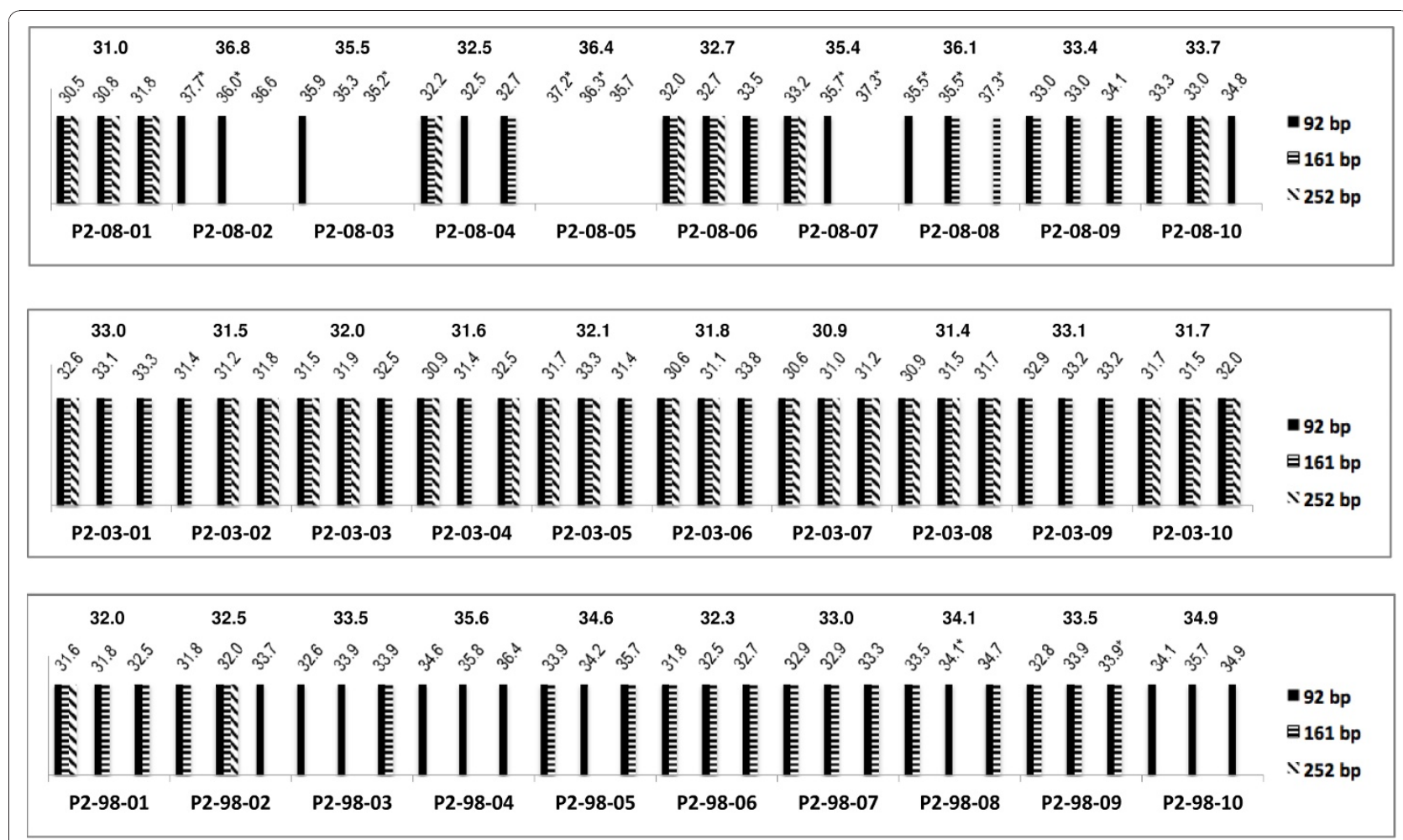

Figure 5 Comparison of the multiplex endpoint RT-PCR and RT-qPCR assays for protocol 2 (P2). The bottom axis identifies the samples. The band sizes obtained for each of the sample replicate are shown as bars. The values on the top of the graph provide both the $C_{q}$ value measured for each sample replicate in the TBP RT-qPCR assay and the mean $C_{q}$ value. Samples labelled with a ${ }^{*}$ symbol indicate a standard deviation between replicates that is greater than 0.5 .

endpoint RT-PCR assay (Figures 4 and 5). Furthermore, all of these samples also amplified the $87 \mathrm{bp}$ amplicon with $\mathrm{C}_{\mathrm{q}}$ values less than 35.1 in the RT-qPCR assay (Figures 4 and 5). The lack of correlation between age of the FFPE samples and RNA quality has been reported previously [36]. This may be explained by a difference in the processing of the samples, such as pre-fixation time, fixation time and storage conditions over the course of time [3,21]. The variation in PCR fragment sizes present in each sample replicate was also the least in the samples prepared in year 2003 compared to samples prepared from the years 1998 and 2008, consistent with a minimisation of stochastic effects caused by greater amounts of template. The effect of sample age needs further investigation.
Table 1 Correlation of the multiplex endpoint RT-PCR and the RT-qPCR assay

\begin{tabular}{|c|c|c|c|}
\hline $\begin{array}{l}\text { Multiplex RT- } \\
\text { PCR }\end{array}$ & Protocol & $\begin{array}{l}\text { No. samples in RT- } \\
\text { PCR }\end{array}$ & $\begin{array}{l}\text { No. samples in RT- } \\
\text { qPCR }\end{array}$ \\
\hline \multirow[t]{2}{*}{$\begin{array}{l}\text { No } \\
\text { amplification }\end{array}$} & P1 & $3 / 90(3 \%)$ & $\begin{array}{l}C q<35.1: 0 \\
C q \geq 35.1: 3\end{array}$ \\
\hline & P2 & $7 / 90(8 \%)$ & $\begin{array}{l}C q<35.1: 0 \\
C q \geq 35.1: 7\end{array}$ \\
\hline \multirow[t]{2}{*}{92 bp } & P1 & 13/90 (15\%) & $\begin{array}{l}C q<35.1: 5 \\
C q \geq 35.1: 8\end{array}$ \\
\hline & P2 & 18/90 (20\%) & $\begin{array}{l}C q<35.1: 10 \\
C q \geq 35.1: 8\end{array}$ \\
\hline \multirow[t]{2}{*}{$>92 \mathrm{bp}$} & P1 & 74/90 (82\%) & $\begin{array}{l}C q<35.1: 73 \\
C q \geq 35.1: 1\end{array}$ \\
\hline & P2 & 65/90 (72\%) & $\begin{array}{l}C q<35.1: 62 \\
C q \geq 35.1: 3\end{array}$ \\
\hline
\end{tabular}

Table 2 Cq values measured by the RT-qPCR assay

\begin{tabular}{lccc}
\hline & $\mathrm{C}_{\mathbf{q}} \leq \mathbf{3 2}$ & $\mathbf{3 2 . 1} \leq \mathrm{C}_{\mathbf{q}} \leq \mathbf{3 5 . 0}$ & $\mathbf{3 5 . 1} \leq \mathrm{C}_{\mathbf{q}} \leq \mathbf{3 9 . 9}$ \\
\hline P1-08 & 5 & 14 & 11 \\
P1-03 & 24 & 6 & 0 \\
P1-98 & 7 & 22 & 1 \\
P1 (total) & $\mathbf{3 6}$ & $\mathbf{4 2}$ & $\mathbf{1 2}$ \\
& & & \\
P2-08 & 4 & 12 & 14 \\
P2-03 & 20 & 10 & 0 \\
P2-98 & 5 & 21 & 4 \\
P2 (total) & $\mathbf{2 9}$ & $\mathbf{4 3}$ & $\mathbf{1 8}$
\end{tabular}

Samples from years 2008, 2003 and 1998 were analysed by each of the two protocols. Each sample of protocol 1 (P1) and 2 (P2) was separated into three groups (based on the $C_{q}$ value measured for each sample replicate). 


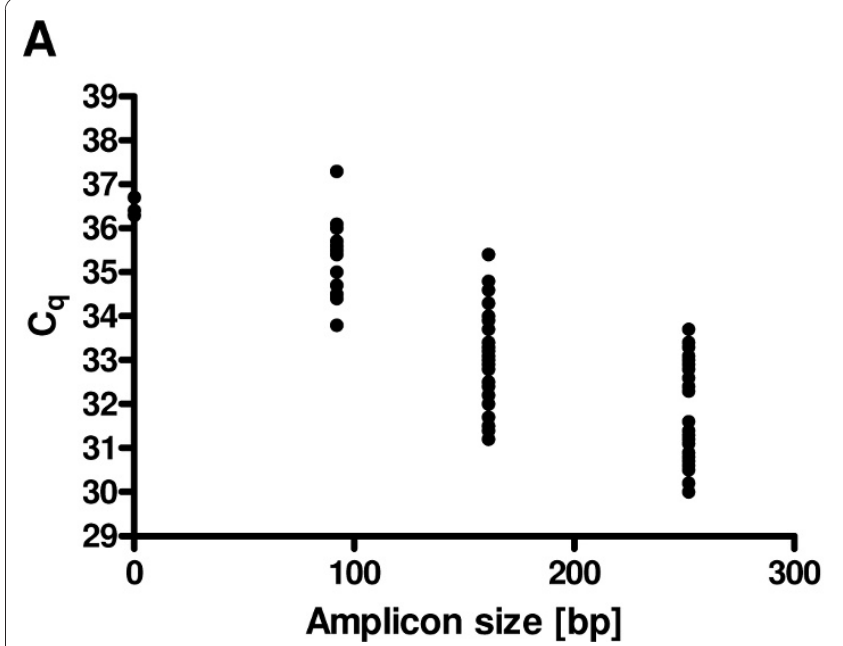

B

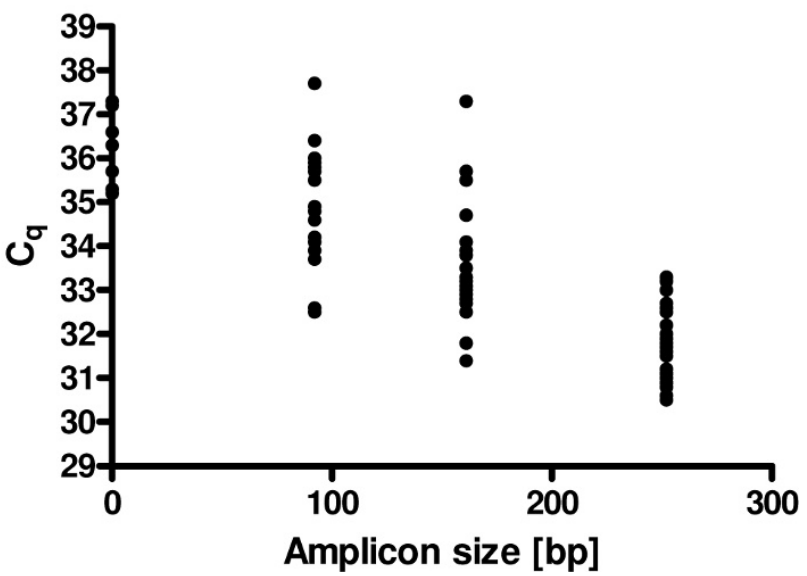

Figure 6 Spearman correlation between fragment size in the multiplex endpoint RT-PCR assay and the appropriate $C_{q}$ value obtained in the RT-qPCR assay. The $x$-axis shows the fragment size and the $y$-axis shows the $C_{q}$ value. Panel A corresponds to protocol 1 (P1) and Panel B corresponds to protocol 2 (P2).

\section{Discussion}

There has been an increasing demand for reliable methods and protocols for the extraction of RNA from FFPE tissue sections. The performance of RNA preparation protocols has improved over the years and specific protocols for certain RNA downstream applications have been developed (reviewed in [1,2]).

Despite the improvements in methodologies for extracting RNA from FFPE specimens, one significant and challenging problem still remains. The quality of the extracted RNA is compromised and the degree of RNA degradation and the extent of chemical modifications of the RNA may limit its use in downstream applications. It is therefore critical to assess the RNA quality at the cDNA stage to identify the RNA preparations which are suitable for a particular RT-qPCR analysis.

The multiplex endpoint RT-PCR approach used in this study has been developed and optimised to assess RNA extracted from FFPE specimens for its use in RTqPCR assays. The assay is sensitive to RNA degradation as well as chemical modifications, which both determine the length of an amplicon during PCR amplification. This methodology is similar in principle to one that has been used extensively in our laboratory for the assessment of DNA from FFPE samples [37].

The choice of the target gene mRNA is of particular importance. It is desirable, that the target gene mRNA is ubiquitously expressed across most cell types and that the level of gene expression shows a similar magnitude among the samples. We selected TBP for our multiplex endpoint RT-PCR assay, because it was shown to be relatively stably expressed in a range of tumour types such as bladder cancer [24], renal cell carcinoma [25], hepatocellular carcinoma [26], glioma [27,29] and breast cancer [28]. TBP is expressed at moderate $[27,29,38]$ to low levels [23]. The choice of a highly expressed target gene mRNA might result in an increased false negative rate for less abundant mRNAs in gene expression studies, due to an insufficient amount of starting material for PCR amplification. This is supported by a study, which showed that only a limited proportion of the RNA extracted from FFPE tissues is actually accessible for cDNA synthesis [39].

We also designed our primers to avoid underlying polymorphic sites. Target gene mRNA from highly polymorphic genes perhaps should be avoided. The primers in a previous approach which used the G6PD gene actually overlie potential polymorphic sites [20]. Primer binding sites which contain polymorphic sites will lead to impaired or even absent PCR amplification of the mismatched alleles.

Our multiplex endpoint RT-PCR approach utilises random primers to synthesise cDNA. Thus after the cDNA is assessed, the same cDNA can subsequently be used in the final gene expression experiment(s). This then also controls for the cDNA synthesis step.

The knowledge about which fragment sizes can be amplified during a RT-qPCR assay helps to identify samples suitable for gene expression analysis and which amplicon sizes can be used for an RT-qPCR assay design. The range of PCR amplicon sizes covered by our assay takes into account the RNA sizes normally obtained from FFPE. The upper size range is interrogated by three PCR amplicon sizes (161, 252 and 300 $\mathrm{bp}$ ), and helps to identify samples suitable for sometimes more demanding applications, such as discrimination 
between gene splice variants. The $92 \mathrm{bp}$ PCR fragment helps to identify samples suitable for FFPE-friendly RTqPCR assays which we normally design with amplicon sizes less than $90 \mathrm{bp}$.

The good agreement between the results observed for the multiplex endpoint RT-PCR assay and the RT-qPCR results (Figure 6) shows that this assay can identify FFPE samples suitable for gene expression studies. The ten samples, which did not amplify in the multiplex endpoint RT-PCR assay amplified all very late in the RT-qPCR assay and would normally have been excluded from further analysis. The 71 samples, which showed amplification of all the amplicon sizes up to $252 \mathrm{bp}$ in the multiplex endpoint RT-PCR assay amplified with moderate $\mathrm{C}_{\mathrm{q}}$ values in the RT-qPCR assay and are probably the best suited samples to deliver reliable gene expression data for most genes of interest in gene expression analysis.

\section{Conclusions}

There is an increasing demand for the use of RNA from FFPE both in research and in molecular diagnostic applications such as the Oncotype DX test $[6,40,41]$. This is accompanied by a need for reliable methodologies to assess the quality of FFPE derived RNA. Most of the approaches currently used for RNA quality control are not suitable or have a limited usage for the assessment of such challenging material.

The validated quality control multiplex endpoint RTPCR assay presented here overcomes the limitations of current approaches and is a robust method and well suited for determining the quality of a RNA preparation, especially for FFPE derived RNA. In addition, the assay can be used for routine quality control assessment of cDNA synthesis. The assay is also applicable for comparing or refining methodologies for RNA extraction and cDNA synthesis. Finally, the approach is cost effective and only requires equipment which is widely available.

\section{Methods}

\section{Archival FFPE tissue samples}

Thirty breast tumour FFPE blocks (ten each from the years 1998, 2003 and 2008) were retrieved from the archives of the Department of Pathology at the Peter MacCallum Cancer Centre. The institutional ethics committee approved the study (Approval number: 03/90).

\section{Histology procedures}

The bench surface, the manual rotary microtome Leica RM2235 (Leica Microsystems), the equipments and glass slides were cleaned with RNaseZap (Ambion, Life Technologies, Austin, TX) prior to use according to the manufacturer's directions. Diethyl pyrocarbonate
(DEPC) (Sigma, St. Louis, MO) treated water $(0.1 \%, \mathrm{v} / \mathrm{v})$ was used throughout the histology procedures.

For haematoxylin and eosin (H\&E) staining, a $3 \mu \mathrm{m}$ section from each FFPE block was stained to identify the tumour enriched area for needle microdissection. From each FFPE block, one to five $7 \mu \mathrm{m}$ sections were prepared and mounted on the glass slides. The number of sections used in microdissection was determined by the content of tumour cells in the tumour enriched marked areas therefore ensuring a adequate amount of tumour cells to be microdissected for each sample. The content of tumour cells in all cases was assessed by a pathologist and was in the range of 40 to $90 \%$. After baking the sections for five minutes on a hotplate at $70^{\circ}$ $\mathrm{C}$, the sections were deparaffinised in three changes of xylene for two minutes each and were taken to water by three changes of $100 \%$ ethanol for two minutes each and DEPC water for two minutes. Subsequently, the sections were stained with $0.5 \%$ methyl green to assist with needle microdissection. FFPE blocks were sectioned freshly just prior to needle microdissection and subsequent total RNA extraction to minimise RNA degradation after sectioning.

\section{RNA extraction and complementary DNA (cDNA) preparation}

Two protocols were used to extract total RNA from FFPE samples. The first protocol utilised the High Pure FFPE RNA Micro Kit (Roche, Mannheim, Germany) and the second protocol utilised TRIzol reagent. The latter protocol was adapted as described from a recently published protocol [8]. The experimental procedures were performed in triplicates, each single experiment on a different day.

In the first protocol referred to as protocol 1 (P1), needle microdissected tissue from each sample was transferred immediately to a $1.5 \mathrm{~mL}$ Eppendorf tube containing $60 \mu \mathrm{L}$ tissue lysis buffer provided by the High Pure FFPE RNA Micro Kit. Total RNA was extracted according to the manufacturer's protocol, eluted in $20 \mu \mathrm{L}$ elution buffer and stored at $-80^{\circ} \mathrm{C}$.

In the second protocol referred to as protocol 2 (P2), needle microdissected tissue from each sample was immediately transferred to a $1.5 \mathrm{~mL}$ Eppendorf tube containing $260 \mu \mathrm{L}$ of the lysis buffer from the Agencourt FormaPure Kit (Beckman Coulter, Beverly, MA) and incubated at $70^{\circ} \mathrm{C}$ for one hour. Subsequently the tube was cooled to room temperature, $20 \mu \mathrm{L}$ proteinase $\mathrm{K}$ provided with the FormaPure Kit was added and incubated at $55^{\circ} \mathrm{C}$ for one hour. The reaction mixture was cooled to room temperature, $500 \mu \mathrm{L}$ TRIzol (Gibco BRL, Life Technologies, Grand Island, NY) and $100 \mu \mathrm{L}$ chloroform were added, vortexed thoroughly and incubated for three minutes. After centrifugation of the tube 
at $12,000 \mathrm{~g}$ for 14 minutes at $4{ }^{\circ} \mathrm{C}$ the upper aqueous layer was immediately transferred into a new $1.5 \mathrm{~mL}$ Eppendorf tube. An equal volume of 2-propanol was added to the aqueous layer, vortexed thoroughly and incubated overnight at $-20^{\circ} \mathrm{C}$. The sample was centrifuged at $12,000 \mathrm{~g}$ for 10 minutes at $4^{\circ} \mathrm{C}$. The supernatant was removed. The RNA pellet was washed with $1 \mathrm{~mL}$ $70 \%$ ethanol $\left(4^{\circ} \mathrm{C}\right)$, vortexed thoroughly and centrifuged at $12,000 \mathrm{~g}$ for five minutes at $4^{\circ} \mathrm{C}$. The supernatant was removed and the $70 \%$ ethanol washing step was repeated. The supernatant was removed again and the RNA pellet was dried for 15 minutes at room temperature and resuspended in $30 \mu \mathrm{L}$ RNase free water. Residual genomic DNA co-extracted with total RNA was digested by DNase treatment employing the Turbo DNA-Free kit (Ambion) according to the manufacturer's instructions in a final volume of $50 \mu \mathrm{L}$. The extracted total RNA was stored at $-80^{\circ} \mathrm{C}$.

Total RNA concentrations were measured by the NanoDrop ND-2000 spectrophotometer (NanoDrop Technologies, Thermo Fisher Scientific, Wilmington, DE) after DNase treatment for each sample derived by each protocol in duplicate. Mean values were used to calculate the total RNA input for cDNA synthesis. RNA purity was estimated by the absorbance ratio $A_{260} / A_{280}$.

One hundred fifty and $75 \mathrm{ng}$ respectively of total RNA was reverse transcribed using the Superscript III Reverse Transcriptase (Invitrogen, Life Technologies, Carlsbad, CA) with $250 \mathrm{ng}$ random hexamers (Pharmacia, Uppsala, Sweden) according to the manufacturer's instructions in the presence of $20 \mathrm{U}$ RNase inhibitor (Roche) in a final volume of $20 \mu \mathrm{L}$. The mixture was incubated for one hour at $55^{\circ} \mathrm{C}$. The resulting cDNA was stored at $-20^{\circ} \mathrm{C}$.

\section{Multiplex endpoint RT-PCR}

Presence or absence of various cDNA fragments synthesized from RNA extracted from the FFPE samples was determined by a multiplex endpoint RT-PCR assay using the TBP mRNA (NM_003194) as the target sequence (Figure 2). The assay conditions were optimised on a cDNA mixture prepared from RNA extracted from different cell lines.

PCR was performed on the Veriti 96-well Thermal Cycler (Applied Biosystems, Life Technologies, Foster City, CA) in a Thermo-Fast 96 PCR Detection Plate MkII (ABgene, Thermo Fisher Scientific, Epsom, United Kingdom) with a final reaction volume of $20 \mu \mathrm{L}$, containing $350 \mathrm{nmol} / \mathrm{L}$ each of the primers 92-F: 5'-GGATAAGAGAGCCACGAACC-3' and 92-R: 5'-TGCCAGTCTGGACTGTTCTT-3', $550 \mathrm{nmol} / \mathrm{L}$ each of the primers 161F: 5'-GGGCACCACTCCACTGTAT-3' and 161-R: 5'CACGAAGTGCAATGGTCTTT-3', $250 \mathrm{nmol} / \mathrm{L}$ each of the primers 252-F: 5'-GGGAGCTGTGATGTGAAGTTT-
3' and 252-R: 5'-TGAGAGCCATTACGTCGTCT-3', 100 $\mathrm{nmol} / \mathrm{L}$ each of the primers 300-F: 5'-GGCGGAAGTGACATTATCAA-3' and 300-R: 5'-CAGGCTGTTGTTCTGATCCA-3' (GeneWorks, Adelaide, Australia), $200 \mu \mathrm{mol} /$ L of each dNTP, 0.5U of HotStarTaq DNA Polymerase (Qiagen, Hilden, Germany) in $1 \times$ of the supplied PCR buffer containing $2.5 \mathrm{mmol} / \mathrm{L} \mathrm{MgCl}_{2}$ and $1 \mu \mathrm{L}$ (if $150 \mathrm{ng}$ of total RNA was used for cDNA preparation) and $2 \mu \mathrm{L}$ (if $75 \mathrm{ng}$ of total RNA was used for cDNA preparation) of undiluted cDNA as template respectively. The initial denaturation $\left(95^{\circ} \mathrm{C}, 15\right.$ minutes $)$ was followed by 40 cycles of 30 seconds at $95^{\circ} \mathrm{C}, 30$ seconds at $60^{\circ} \mathrm{C}$ and 30 seconds at $72^{\circ} \mathrm{C}$, and a final extension step at $72^{\circ} \mathrm{C}$ for seven minutes. Genomic DNA extracted from peripheral blood from normal individuals $(2 \mathrm{ng} / \mu \mathrm{L})$ was used as negative control and a cDNA mixture prepared from total RNA of different cell lines served as a positive control. Each sample was analysed once.

The PCR products were evaluated for band abundance and size by agarose gel electrophoresis. The samples were run on a $2 \%(\mathrm{w} / \mathrm{v})$ agarose gel in a $1 \times$ TBE Buffer system and stained with ethidium bromide. The wells were loaded with $20 \mu \mathrm{L}$ of the PCR product mixture with $5 \mu \mathrm{L} 5 \times$ loading dye. One $\mu \mathrm{L}$ pUC19/HpaII DNA Molecular Weight Marker (GeneWorks) was run alongside the PCR products to determine their size.

\section{Reverse transcription - quantitative real-time PCR (RT- qPCR)}

PCR was performed on the LightCycler 480 Instrument (Roche). Resulting data were analysed and quantified with the LightCycler 480 software release 1.5.0 (Roche), utilising the second derivative maximum method [42]. The calculated $C_{P}$ (Crossing Point) value corresponds to the current recommended term $\mathrm{C}_{\mathrm{q}}$ (Quantification Cycle) value [33].

PCR was performed in LightCycler 480 Multiwell Plate 384 plates (Roche) in a final reaction volume of $10 \mu \mathrm{L}$ using the TBP mRNA (NM_003194) as the target sequence (Figure 2). The TBP RT-qPCR assay was designed and optimised as described previously [32]. 300 nmol/L of the forward primer RT-qPCR-F: 5'-GAACATCATGGATCAGAACAACA-3' and $200 \mathrm{nmol} / \mathrm{L}$ of the reverse primer RT-qPCR-R: 5'-ATAGGGATTCCGGGAGTCAT-3' (GeneWorks) were mixed in $1 \times$ LightCycler 480 Probes Master (Roche) containing $100 \mathrm{nmol} / \mathrm{L}$ of the human Universal Probe Library probe \#87 (Roche), and $1 \mu \mathrm{L}$ (if $150 \mathrm{ng}$ of total RNA was used for cDNA preparation) or $2 \mu \mathrm{L}$ (if $75 \mathrm{ng}$ of total RNA was used for cDNA preparation) of undiluted cDNA as template respectively. The initial denaturation $\left(95^{\circ} \mathrm{C}, 10\right.$ minutes $)$ was followed by 45 cycles of 10 seconds at $95^{\circ} \mathrm{C}$, 30 seconds at $60^{\circ} \mathrm{C}$, and a final cooling step at $40^{\circ} \mathrm{C}$ for 30 seconds. Each sample was analysed in duplicate. 


\section{Statistical analysis}

Statistical analyses were performed using GraphPad Prism version 5.03 for Windows (GraphPad Software, San Diego, CA, http://www.graphpad.com). Where appropriate, data are presented as the mean \pm standard deviation (SD). Nonparametric correlations between a longer amplicon size in the multiplex endpoint RT-PCR assay and the appropriate $\mathrm{C}_{\mathrm{q}}$ value obtained in $\mathrm{RT}$ qPCR were evaluated by calculating the Spearman correlation coefficient. A two-tailed $P$-value (calculated by Gaussian approximation) of $<0.05$ was considered to be statistically significant for each correlation.

\section{Acknowledgements}

The authors thank Max Yan for excellent pathological assistance, Sue Sturrock and Raul Sestoso for technical assistance and specimen retrieval and Christoph Bock for helpful comments. This research was supported by the Victorian Breast Cancer Research Consortium and a grant to AD from Susan G. Komen for the Cure.

\section{Author details}

'Molecular Pathology Research and Development Laboratory, Department of Pathology, Peter MacCallum Cancer Centre, East Melbourne, Victoria 3002, Australia. ${ }^{2}$ Department of Pathology, The University of Melbourne, Parkville, Victoria 3010, Australia.

\section{Authors' contributions}

EAT, TM and DJB carried out the experiments. TM, EAT and AD conceived the experiments and analysed the data. SBF, AD and TM initiated the project and supervised the work. All authors contributed important ideas throughout the project and were involved in the writing of the manuscript All authors have read and approved the manuscript.

\section{Competing interests}

The authors declare that they have no competing interests.

Received: 29 July 2010 Accepted: 17 December 2010

Published: 17 December 2010

\section{References}

1. Farragher SM, Tanney A, Kennedy RD, Harkin DP: RNA expression analysis from formalin fixed paraffin embedded tissues. Histochem Cell Biol 2008, 130:435-445.

2. Medeiros F, Rigl CT, Anderson GG, Becker SH, Halling KC: Tissue handling for genome-wide expression analysis: a review of the issues, evidence, and opportunities. Arch Pathol Lab Med 2007, 131:1805-1816.

3. von Ahlfen S, Missel A, Bendrat K, Schlumpberger M: Determinants of RNA quality from FFPE samples. PLoS One 2007, 2:e1261.

4. Masuda N, Ohnishi T, Kawamoto S, Monden M, Okubo K: Analysis of chemical modification of RNA from formalin-fixed samples and optimization of molecular biology applications for such samples. Nucleic Acids Res 1999, 27:4436-4443.

5. Park YN, Abe K, Li H, Hsuih T, Thung SN, Zhang DY: Detection of hepatitis $C$ virus RNA using ligation-dependent polymerase chain reaction in formalin-fixed, paraffin-embedded liver tissues. Am J Pathol 1996, 149:1485-1491.

6. Cronin M, Pho M, Dutta D, Stephans JC, Shak S, Kiefer MC, Esteban JM, Baker JB: Measurement of gene expression in archival paraffinembedded tissues: development and performance of a 92-gene reverse transcriptase-polymerase chain reaction assay. Am J Pathol 2004, 164:35-42

7. Antonov J, Goldstein DR, Oberli A, Baltzer A, Pirotta M, Fleischmann A, Altermatt HJ, Jaggi R: Reliable gene expression measurements from degraded RNA by quantitative real-time PCR depend on short amplicons and a proper normalization. Lab Invest 2005, 85:1040-1050.
8. Waddell N, Cocciardi S, Johnson J, Healey S, Marsh A, Riley J, Silva Ld, Vargas AC, Reid L, KConFab Investigators, et al: Gene expression profiling of formalin-fixed, paraffin-embedded familial breast tumours using the whole genome-DASL assay. J Pathol 2010, 221:452-461.

9. Bibikova M, Talantov D, Chudin E, Yeakley JM, Chen J, Doucet D, Wickham E, Atkins D, Barker D, Chee M, et al: Quantitative gene expression profiling in formalin-fixed, paraffin-embedded tissues using universal bead arrays. Am J Pathol 2004, 165:1799-1807.

10. Specht K, Richter T, Muller U, Walch A, Werner M, Hofler H: Quantitative gene expression analysis in microdissected archival formalin-fixed and paraffin-embedded tumor tissue. Am J Pathol 2001, 158:419-429.

11. Fleige S, Pfaffl MW: RNA integrity and the effect on the real-time qRTPCR performance. Mol Aspects Med 2006, 27:126-139.

12. Penland SK, Keku TO, Torrice C, He X, Krishnamurthy J, Hoadley KA, Woosley JT, Thomas NE, Perou CM, Sandler RS, et al: RNA expression analysis of formalin-fixed paraffin-embedded tumors. Lab Invest 2007, 87:383-391.

13. Glasel JA: Validity of nucleic acid purities monitored by $260 \mathrm{~nm} / 280 \mathrm{~nm}$ absorbance ratios. Biotechniques 1995, 18:62-63.

14. Manchester KL: Value of A260/A280 ratios for measurement of purity of nucleic acids. Biotechniques 1995, 19:208-210.

15. Manchester KL: Use of UV methods for measurement of protein and nucleic acid concentrations. Biotechniques 1996, 20:968-970.

16. Imbeaud S, Graudens E, Boulanger V, Barlet X, Zaborski P, Eveno E, Mueller O, Schroeder A, Auffray C: Towards standardization of RNA quality assessment using user-independent classifiers of microcapillary electrophoresis traces. Nucleic Acids Res 2005, 33:e56.

17. Schroeder A, Mueller O, Stocker S, Salowsky R, Leiber M, Gassmann M, Lightfoot S, Menzel W, Granzow M, Ragg T, et al: The RIN: an RNA integrity number for assigning integrity values to RNA measurements. BMC Mol Biol 2006, 7:3.

18. Auer H, Lyianarachchi S, Newsom D, Klisovic Ml, Marcucci G, Kornacker K: Chipping away at the chip bias: RNA degradation in microarray analysis. Nat Genet 2003, 35:292-293.

19. Nolan T, Hands RE, Bustin SA: Quantification of mRNA using real-time RTPCR. Nat Protoc 2006, 1:1559-1582.

20. Liu H, Huang X, Zhang Y, Ye H, El Hamidi A, Kocjan G, Dogan A, Isaacson PG, Du M-Q: Archival fixed histologic and cytologic specimens including stained and unstained materials are amenable to RT-PCR. Diagn Mol Pathol 2002, 11:222-227.

21. van Maldegem F, de Wit M, Morsink F, Musler A, Weegenaar J, van Noesel, Carel JM: Effects of processing delay, formalin fixation, and immunohistochemistry on RNA Recovery From Formalin-fixed Paraffinembedded Tissue Sections. Diagn Mol Pathol 2008, 17:51-58.

22. Fedorowicz G, Guerrero S, Wu TD, Modrusan Z: Microarray analysis of RNA extracted from formalin-fixed, paraffin-embedded and matched freshfrozen ovarian adenocarcinomas. BMC Med Genomics 2009, 2:23.

23. Radonic A, Thulke S, Mackay IM, Landt O, Siegert W, Nitsche A: Guideline to reference gene selection for quantitative real-time PCR. Biochem Biophys Res Commun 2004, 313:856-862.

24. Ohl F, Jung M, Radonic A, Sachs M, Loening SA, Jung K: Identification and validation of suitable endogenous reference genes for gene expression studies of human bladder cancer. J Urol 2006, 175:1915-1920.

25. Jung M, Ramankulov A, Roigas J, Johannsen M, Ringsdorf M, Kristiansen G, Jung $K$ : In search of suitable reference genes for gene expression studies of human renal cell carcinoma by real-time PCR. BMC Mol Biol 2007, 8:47.

26. Gao Q, Wang X-Y, Fan J, Qiu S-J, Zhou J, Shi Y-H, Xiao Y-S, Xu Y, Huang XW, Sun J, et al: Selection of reference genes for real-time PCR in human hepatocellular carcinoma tissues. J Cancer Res Clin Oncol 2008, 134:979-986.

27. Valente V, Teixeira SA, Neder L, Okamoto OK, Oba-Shinjo SM, Marie SKN, Scrideli CA, Paco-Larson ML, Carlotti CGJ: Selection of suitable housekeeping genes for expression analysis in glioblastoma using quantitative RT-PCR. BMC Mol Biol 2009, 10:17.

28. Drury $\mathrm{S}$, Anderson H, Dowsett M: Selection of REFERENCE genes for normalization of qRT-PCR data derived from FFPE breast tumors. Diagn Mol Pathol 2009, 18:103-107.

29. Kreth S, Heyn J, Grau S, Kretzschmar HA, Egensperger R, Kreth FW: Identification of valid endogenous control genes for determining gene expression in human glioma. Neuro Oncol 2010, 12:570-579. 
30. Wilfinger WW, Mackey K, Chomczynski P: Effect of pH and ionic strength on the spectrophotometric assessment of nucleic acid purity. Biotechniques 1997, 22:474-6-478-81.

31. Mouritzen P, Nielsen PS, Jacobsen N, Noerholm M, Lomholt C Pfundheller HM, Ramsing NB, Kauppinen S, Tolstrup N: ProbeLibrary Expression profiling $99 \%$ of all human genes using only 90 dual-labeled real-time PCR Probes. Biotechniques 2004, 37:492-495.

32. Mikeska T, Dobrovic A: Validation of a primer optimisation matrix to improve the performance of reverse transcription - quantitative realtime PCR assays. BMC Res Notes 2009, 2:112

33. Bustin SA, Benes V, Garson JA, Hellemans J, Huggett J, Kubista M, Mueller R, Nolan T, Pfaffl MW, Shipley GL, et al: The MIQE guidelines: minimum information for publication of quantitative real-time PCR experiments. Clin Chem 2009, 55:611-622.

34. Gallup JM, Ackermann MR: The 'PREXCEL-Q Method' for qPCR. Int J Biomed Sci 2008, 4:273-293.

35. Mestdagh P, Feys T, Bernard N, Guenther S, Chen C, Speleman F, Vandesompele Jo: High-throughput stem-loop RT-qPCR miRNA expression profiling using minute amounts of input RNA. Nucleic Acids Res 2008, 36:e143.

36. Ribeiro-Silva A, Zhang H, Jeffrey SS: RNA extraction from ten year old formalin-fixed paraffin-embedded breast cancer samples: a comparison of column purification and magnetic bead-based technologies. BMC Mol Biol 2007, 8:118.

37. van Dongen JJM, Langerak AW, Bruggemann M, Evans PAS, Hummel M, Lavender FL, Delabesse E, Davi F, Schuuring E, Garcia-Sanz R, et al: Design and standardization of PCR primers and protocols for detection of clonal immunoglobulin and T-cell receptor gene recombinations in suspect lymphoproliferations: report of the BIOMED-2 Concerted Action BMH4-CT98-3936. Leukemia 2003, 17:2257-2317.

38. Ohl F, Jung M, Xu C, Stephan C, Rabien A, Burkhardt M, Nitsche A Kristiansen G, Loening SA, Radonic A, et al: Gene expression studies in prostate cancer tissue: which reference gene should be selected for normalization? J Mol Med 2005, 83:1014-1024.

39. Godfrey TE, Kim SH, Chavira M, Ruff DW, Warren RS, Gray JW, Jensen RH: Quantitative mRNA expression analysis from formalin-fixed, paraffinembedded tissues using $5^{\prime}$ nuclease quantitative reverse transcriptionpolymerase chain reaction. J Mol Diagn 2000, 2:84-91.

40. Paik S, Shak S, Tang G, Kim C, Baker J, Cronin M, Baehner FL, Walker MG, Watson D, Park T, et al: A multigene assay to predict recurrence of tamoxifen-treated, node-negative breast cancer. N Engl J Med 2004 351:2817-2826.

41. Cronin M, Sangli C, Liu M-L, Pho M, Dutta D, Nguyen A, Jeong J, Wu J, Langone KC, Watson D, et al: Analytical validation of the Oncotype DX genomic diagnostic test for recurrence prognosis and therapeutic response prediction in node-negative, estrogen receptor-positive breast cancer. Clin Chem 2007, 53:1084-1091.

42. Rasmussen R: Quantification on the LightCycler. In Rapid Cycle Real-Time PCR: Methods and Applications. Edited by: Meuer SC, Wittwer C, Nakagawara K. Springer, Heidelberg, Germany; 2001:21-34.

doi:10.1186/1472-6750-10-89

Cite this article as: Takano et al:: A multiplex endpoint RT-PCR assay for quality assessment of RNA extracted from formalin-fixed paraffinembedded tissues. BMC Biotechnology 2010 10:89.

\section{Submit your next manuscript to BioMed Central and take full advantage of:}

- Convenient online submission

- Thorough peer review

- No space constraints or color figure charges

- Immediate publication on acceptance

- Inclusion in PubMed, CAS, Scopus and Google Scholar

- Research which is freely available for redistribution

Submit your manuscript at www.biomedcentral com/submit
C Biomed Central 